\title{
Genel Doğrusal ve Çok Seviyeli Doğrusal Büyüme Modelleri Kullanılarak Etlik Piliçlerde Büyümenin Değerlendirilmesi*
}

\author{
Volkan IZGi' $\dot{1}^{1}$, Suna AKKOL ${ }^{2 * *}$, Ahmet TEKELI' ${ }^{2}$ \\ ${ }^{1}$ Zeve Ilköğretim Okulu, Van, TÜRKIYYE \\ ${ }^{2}$ Van Yüzüncü Yıl Üniversitesi, Ziraat Fakültesi, Zootekni Bölümü, Van, TÜRKIYYE
}

\begin{tabular}{|c|c|}
\hline Geliş Tarihi/Received: 21.02 .2020 & Kabul Tarihi/Accepted: 30.06 .2020 \\
\hline \multicolumn{2}{|l|}{ ORCID ID (Yazar sırasina göre / by author order) } \\
\hline (1D) orcid.org/0000-0001-5417-1962 (D) orcid.org/0000-0001-5 & rcid.org/0000-0002-6525-7267 \\
\hline
\end{tabular}

"Sorumlu Yazar/Corresponding Author: sgakkol@yyu.edu.tr

Öz: Bu çalışma, genel doğrusal ve çok seviyeli doğrusal büyüme modellerini kullanarak büyüme eğrisi modellerini karşılaştırmak ve etlik piliçlerde büyümedeki farklılıkların tespit edilmesi amacıyla yapılmıştır. Bu amaçla 74 erkek etlik pilicin canlı ağırlık kayıtlarını içeren veri seti kullanılmıştır. Ölçümler yumurtadan çıkıştan altıncı haftaya kadar haftada bir olmak üzere bireysel olarak kaydedilmiștir. Verilerin analizi için, genel doğrusal modellerden iki ve çok seviyeli doğrusal modellerden üç olmak üzere beş farklı büyüme modeli kullanılmıştır. Değişimi en iyi açıklayan modeli bulmak için; log olabilirlik (log-likelihood, ll), Akaiki bilgi ölçütü (Akaike Information Criteria, AIC), Bayes bilgi ölçütü (Bayesian Information Criteria, BIC), düzeltilmiş Akaiki bilgi ölçütü (AIC Corrected, AICC) ve olabilirlik oran testi (Likelihood Ratio Test, LRT)'nden faydalanılmıştır. Çalışmanın sonuçları, çok seviyeli büyüme modellerinin genel doğrusal modellerden daha hassas tahminler yaptığını ve büyümeyi en iyi açılayan modelin en küçük uyum ölçütlerine sahip "kesim noktası ve eğimin şansa bağlı olduğu kuadratik büyüme modeli" olduğunu ortaya koymuştur. Bu modele göre, erkek etlik piliçlerde büyüme üzerine zamanın lineer ve kuadratik etkisiyle birlikte yumurtadan çıkıştan itibaren büyümenin takip edildiği süre boyunca bireysel farklılıkların anlamlı olduğu sonucuna varılmıştır.

Anahtar Kelimeler: Ross etlik piliç, büyüme eğrisi, hiyerarşik veri, tekrarlamalı ölçüm, kovaryans yapısı

\section{Evaluation of Growth in Broiler Chicken Using General Linear and Multi-Level Linear Growth Models}

\begin{abstract}
This study was conducted to compare the growth curve models using general linear and multi-level linear growth models and to determine the differences in growth in broiler chickens. For this purpose, a data set containing live weight records of 74 male broiler chickens was used. The measurements were recorded individually, once a week, from hatching to the sixth week. For the analysis of the data, five different growth models, two of the general linear models, and three of the multi-level linear models were used. To find the model that best explains the change; log-likelihood (11), Akaike information criterion (AIC), Bayes information criterion (BIC), corrected Akaike information criterion (AICC) and Likelihood ratio test (LRT) were used. The results of the study showed that multi-level growth models make more precise predictions than general linear models, and the model that best describes growth is the "random intercept and random slope quadratic growth model" with the smallest fit criteria. According to this model, it was demonstrated that the chickens had significantly different weights since hatching, where the linear and quadratic effect on growth was significant in male broiler chickens, and that individual differences continued significantly during the period of growth.
\end{abstract}

Keywords: Ross broiler, growth curve, hierarchical data, repeated measurement, covariance structure

": Bu çalı̧̧ma, Van Yüzüncü Yıl Üniversitesi, Fen Bilimleri Enstitüsü tarafından kabul edilen birinci yazara ait "Çok Seviyeli Doğrusal, Genel Doğrusal ve Doğrusal Olmayan Büyüme Modellerinin İncelenmesi ve Hayvancılık Alanında Uygulaması" isimli Yüksek Lisans Tez çalışmasından üretilmiştir. 


\section{Giriş}

İnsanların sağlıklı bir şekilde hayatlarını devam ettirebilmesi dengeli beslenme ile mümkün olmaktadır. Hayvansal protein kaynakları dengeli beslenme için son derece önemli besin gruplarından biridir. Kanatlı eti hayvansal protein kaynakları içinde ayrı bir öneme sahip olup, bu protein kaynağına ülkesel ve küresel talebin giderek artacağı tahmin edilmektedir. Bununla birlikte diğer çiftlik hayvanlarına göre kanatlı üretiminin daha kısa sürede yapılabilmesi, yemden yararlanma oranlarının diğer çiftlik hayvanlarından daha iyi olması, üretim maliyetinin düşük ve karlılığın yüksek olması, kanatlı üretimine yönelmeyi sağlamıştır. Ayrıca kanatlı üretiminin diğer çiftlik hayvanlarına göre daha çevre dostu olması kanatlı üretiminin tercih edilme nedenlerinin bir diğeridir. Tüm bu nedenlerden dolayı, tüketici açısından kanatlı etine ulaşım, hem kolay hem de daha ekonomik olmaktadır.

Canlının, zaman içinde kütle ve hacminde meydana gelen niceliksel artış şeklinde tanımlanan büyüme, diğer bir ifade ile zaman içinde bir canlının ağırlığı ve beden ölçülerinde meydana gelen değişim olarak tanımlanmaktadır (Çolak ve ark., 2006a, 2006b; Y1ldız ve ark., 2009). Büyüme eğrisi, canlının genetik potansiyeli ve çevresel faktörlerin etkisi altında şekillenen, canlının ağırlığı ve zaman ya da yaşı arasındaki istatistiksel ilişkiyi göstermektedir (Akbulut ve ark., 2004). Buna göre büyüme eğrisi aynı zamanda "ağırlıkyaş” eğrisi olarak tanımlanmıştır (Efe, 1990). Büyüme eğrisinin şekli; canlının türüne, yetiştirildiği çevre koşullarına ve incelenen özelliğine göre değişiklik göstermektedir (Efe, 1990; Bilgin ve Esenbuğa, 2003).

Hayvancılık alanında çalışan araştırmacılar tarafından canlıda meydana gelen büyümenin açıklanabilmesi amacıyla çeşitli büyüme eğrisi modelleri kullanılmıştır (Kocabaş ve ark., 1997; Yıldız ve ark., 2009). Canlıların büyümeleri her zaman doğrusal modellerle açıklanamadığı için büyümenin modellenmesinde doğrusal olmayan modellerin kullanılmasına ihtiyaç duyulmuştur (Bilgin ve Esenbuğa, 2003). Negatif Eksponensiyal, Brody, Lojistik, Gompertz, Bertalanffy, Richards, Weibull gibi doğrusal olmayan büyüme eğrisi modelleri, etlik piliçlerin büyümesini modellemek amaciyla çeşitli araştırmacılar tarafından sıklıkla kullanılmıştır (Zhao ve ark., 2015; Alkan ve Birgül, 2016; Michalczuk ve ark., 2016; Demuner ve ark., 2017; Masoudi ve Azarfar, 2017; Araújo ve ark., 2018; Eleroğlu ve ark., 2018).

Büyüme verileri aslında zaman içinde tekrarlamalı olarak elde edilen veriler olup hiyerarşik veya sınıflandırılmış yapıya sahiptirler. $\mathrm{Bu}$ tip veriler için kullanılan modeller, hiyerarşik veya çok seviyeli modeller olarak tanımlanmaktadır (Golstein, 2011). Büyüme verilerinde tekrarlamalı ölçümler bireyler içinde sınıflandırılmıştır. Bu hali ile bireyler seviye-2 ve bireylerden zamana bağlı olarak alınan veriler seviye-1 birimlerini göstermektedir. Çok seviyeli modelleme mantığında büyüme verileri, iki seviyeli bir yapıya sahip olmaktadır (Singer, 1998; Van Der Leeden, 1998; Hedeker, 2004; Kristjansson ve ark., 2007; Akkol ve ark., 2018, Ghaderi-Jzefrehei ve ark., 2018). Sosyal bilimler başta olmak üzere çeşitli çalışma alanlarında kullanılan çok seviyeli modeller son yıllarda hayvancılık alanındaki verilerin analiz edilmesinde de kullanılmaya başlanmıştır (Simsek ve Firat, 2011; Akkol ve ark., 2018; Ghaderi-Jzefrehei ve ark., 2018).

$\mathrm{Bu}$ çalışmada, yumurtadan çıkıştan itibaren altıncı haftaya kadar bireysel ağırlıkları alınmış Ross erkek etlik piliçlerin büyüme eğrisinin genel doğrusal regresyon ve iki seviyeli koşulsuz doğrusal regresyon modelleri kullanılarak elde edilmesi ve büyümeyi en iyi açıklayan modelin bulunması amaçlanmıştır.

\section{Materyal ve Yöntem}

\subsection{Materyal}

Çalışmanın veri setini bireysel kafeslerde büyütülen 74 adet Ross erkek etlik piliçlerden alınan ağırlık ölçümleri oluşturmaktadır. Bireysel olarak alınan ölçümlerin ilki yumurtadan çıkış ağırlığ1 ve diğerleri haftada bir olmak üzere altı hafta süreyle tartımı yapılmış ağırlıkları göstermektedir. Her bir etlik piliçten toplamda yedi kez yapılan ölçümler veri setinin tamamını oluşturmaktadır.

\subsection{Yöntem}

Doğrusal regresyon modelleri, canlılardaki büyüme seyrinin bazı dönemlerde sabit gerçekleştiği durumlarda kullanılan modellerdir. Çalışmada kullanılan doğrusal modeller zamana bağlı değişimin basit etkisinin incelendiği lineer model ve zamanın basit etkisinin yanı sıra ikinci dereceden etkisinin de incelendiği kuadratik modellere ilişkin denklemler sırasıyla Eşitlik 1 ve 2'de verilmiştir.

$$
\begin{aligned}
& Y_{t}=\beta_{0}+\beta_{1} t+e_{t} \\
& Y_{t}=\beta_{0}+\beta_{1} t+\beta_{2} t^{2}+e_{t}
\end{aligned}
$$

$\mathrm{Bu}$ eşitliklerde, $\mathrm{Y}_{\mathrm{t}}$, t'ninci günlük yaşta gözlenen ağırlığı; t, ağırlığın alındığı zamanı 
göstermektedir. Doğrusal modellerde $\beta_{0}$, incelenen özellik bakımından doğrunun y eksenini kestiği başlangıç değeri, bir diğer ifadeyle kesim noktasıdır. $\beta_{1}$ ve $\beta_{2}$ doğrusal modellerdeki regresyon katsayılarını gösterir.

Çok seviyeli doğrusal modeller başlığı altında iki seviyeli koşulsuz doğrusal büyüme modelleri kullanılmıştır. İki seviyeli bir modelde büyüme verilerinin tekrarlamalı ölçümleri seviye-1 ve ölçümün alındığı civcivler seviye-2 olarak ifade edilir. Bu modellerde zaman dışında herhangi bir bağımsız değişken yer almaz. Çalışmada, "kesim noktasinin şansa bağlı olduğu doğrusal büyüme modeli" (Model I), "kesim noktast ve eğimin şansa bağgl olduğu doğrusal büyüme modeli" (Model II) ve "kesim noktast ve eğimin şansa bağl olduğu kuadratik büyüme modeli" (Model III) kullanılmıştır. $\mathrm{Bu}$ modellere ilişkin eşitlikler (Eşitlik 3-11) sırasıyla aşağıda verilmiştir.

$$
\text { Model I: Seviye-1: } \begin{aligned}
& Y_{t i}=\pi_{0 i}+\pi_{1 i} T_{t i}+e_{t i} \\
& \text { Seviye-2: }: \begin{array}{l}
\pi_{0 i}=\beta_{00}+u_{0 i} \\
\pi_{1 i}=\beta_{10}
\end{array}
\end{aligned}
$$

Seviye 2'de verilenler seviye 1'de yerine konulduğunda, 5 numaralı Eşitlik aşağıdaki gibi yazılmaktadır.

$$
Y_{t i}=\beta_{00}+\beta_{10} T_{t i}+u_{0 i}+e_{t i}
$$

Eşitlik 5 'te $Y_{t i}$, $i$ 'inci civcivin $t^{\prime}$ inci ölçüm zamanındaki canlı ağırlığını; $T_{t i}$, i'inci birey için t'inci ölçüm zamanını gösteren zaman değişkenini; $\beta_{00}$, kesim noktası, yani zamanın sıfır olduğu noktada civcivlerin genel-ortalama canlı ağırlık skorunu ve $\beta_{10}$, eğimi yani zamana göre canlı ağırlık skorundaki ortalama değişim miktarını ifade etmektedir. Eşitlik 5 'te yer alan $u_{0 i}$, seviye-2 hata terimi olup $\mathbf{u}_{i}=u_{0 i} \sim N\left(0, \sigma_{u_{0}}^{2}\right)$ ve $e_{t i}$, seviye-1 hata terimi olup $e_{t i} \sim N\left(0, \sigma_{e}^{2}\right)$ varsayımına sahiptir.

$$
\begin{aligned}
\text { Model II: Seviye-1: } Y_{t i} & =\pi_{0 i}+\pi_{1 i} T_{t i}+e_{t i} \\
\text { Seviye-2: } & \begin{aligned}
\pi_{0 i} & =\beta_{00}+u_{0 i} \\
\pi_{1 i} & =\beta_{10}+u_{1 i}
\end{aligned}
\end{aligned}
$$

Seviye-2'de verilenler seviye-1'de yerine konulduğunda 8 numaralı Eşitlik elde edilir.

$$
Y_{t i}=\beta_{00}+\beta_{10} T_{t i}+u_{1 i} T_{t i}+u_{0 i}+e_{t i}
$$

Burada $Y_{t i}, T_{t i}, \beta_{00}, \beta_{10}$ daha önce açıklandığı gibidir. $\mathbf{u}_{i}$ ile $e_{t i}$ hataları birbirinden bağımsız olup $e_{t i} \sim N\left(0, \sigma_{e}^{2}\right), \quad \mathbf{u}_{i}=\left[u_{0 i}, u_{1 i}\right]^{T} \sim N\left(\mathbf{0}, \boldsymbol{\Omega}_{u}\right)$ tanımlaması yapılır.

Model III: Seviye 1:

$$
\begin{array}{r}
Y_{t i}=\pi_{0 i}+\pi_{1 i} T_{t i}+\pi_{2 i} T_{t i}^{2}+e_{t i} \\
\pi_{0 i}=\beta_{00}+u_{0 i} \\
\text { Seviye- } 2: \begin{aligned}
& \pi_{1 i}=\beta_{10}+u_{1 i} \\
& \pi_{2 i}= \beta_{20} \\
& Y_{t i}=\beta_{00}+\beta_{10} T_{t i}+\beta_{20} T_{t i}^{2}+u_{1 i} T_{t i}+u_{0 i}+e_{t i}
\end{aligned}
\end{array}
$$

$\mathrm{Bu}$ modelde zamanın doğrusal etkisiyle birlikte zamanın kuadratik etkisi de modele dahil edilmiştir $\left(T_{t i}^{2}\right)$. Yukarıda 11 numaralı eşitlikte yer alan sabit ve şansa bağlı etkilere ilişkin açıklamalar daha önce yapıldığı gibidir.

Çok seviyeli bir model için tahmin yapılması, aslında genel doğrusal karışı bir modelde (General Linear Mixed Model, GLMM) tahmin yapılmasına benzer olmaktadır. Zira GLMM doğrusal tahmin denklemine şansa bağlı etki veya etkilerin ilave edilmesi ile elde edilen bir modeldir (Breslow ve Clayton, 1993; Lin ve Breslow, 1996). GLMM'de olduğu gibi iki seviyeli bir regresyon modeli için 12 numaralı Eşitlik aşağıdaki gibi yazılmaktadır.

$$
y=X \beta+Z u+e
$$

Burada $X$ ve $Z$, sırasıyla sabit ve şansa bağlı etkilere ait desen matrisi; $\beta$ ve $u$, sabit ve şansa bağlı etkilere ait parametre vektörü; e, hata vektörüdür. $y$ değişkeni için normal dağılımlı olduğu varsayıldığında model için; $y \mid u \sim M V N(X \beta+Z u, R), \quad u \sim M V N(0, G)$ ve e $\sim \operatorname{MVN}(0, R)$ varsayımları yapılmaktadır. Bu varsayımlar diğer bir ifade ile 13 numaralı eşitlikte verildiği gibi olur.

$$
E\left[\begin{array}{l}
\vec{u} \\
\vec{e}
\end{array}\right]=\left[\begin{array}{l}
\overrightarrow{0} \\
\overrightarrow{0}
\end{array}\right] \text { ve } \operatorname{Var}\left[\begin{array}{l}
\vec{u} \\
\vec{e}
\end{array}\right]=\left[\begin{array}{ll}
\vec{G} & \overrightarrow{0} \\
\overrightarrow{0} & \vec{R}
\end{array}\right]
$$

Buna göre y değişkeninin varyansı $\operatorname{Var}(y)=V=\vec{Z} \vec{G} \vec{Z}^{\prime}+\vec{R}$ olur. Burada Z şansa bağlı etkilerin desen matrisidir. $\vec{G}$ ve $\vec{R}$ 'nin yapısına göre uygun kovaryans matrisi kullanılarak modellerin uyumu yapılmıştır. $\mathrm{Bu}$ amaçla tahmin yöntemi olarak En Çok Olabilirlik (Maximum 
Likelihood, ML) ve Kısıtlanmış En Çok Olabilirlik (Restricted Maximum Likelihood, REML) yöntemlerini esas alan İteratif Genelleştirilmiş En Küçük Kareler (Iterative Generalised Least Squares, IGLS) ve Kısıtlanmış İteratif Genelleştirilmiş En Küçük Kareler (Resrticted Iterative Generalised Least Squares, RIGLS) tahmin yöntemleri (Goldstein, 2011) ile birinci derecede Autoregressive (AR1), Bileşik Simetri (Compound Symetri, CS), Yapisal Olmayan (Unstructured, UN), Toepliz (Toep), Heterojen Birinci Dereceden Autoregresive (Heteregenous AR1, ARH1), Heterojen Bileşik Simetri (Heteregenous CS, CSH), Heterojen Toepliz (Heteregenous Toep, ToepH) kovaryans yapıları kullanılmıştır.

Kovaryans yapısının belirlenmesi ve model seçimi için Log olabilirlik (Log-likelihood, $l l$ ), Akaiki Bilgi Ölçütü (Akaike Information Criteria, AIC), Bayes Bilgi Ölçütü (Bayesian Information Criteria, BIC) ve düzeltilmiş Akaiki Bilgi Ölçütü (AIC Corrected, AICC) kullanılan uyum ölçütleridir. AIC, log-olabilirlik ve parametre sayısını (Akaike, 1974), BIC ise log-olabilirlik ve parametre sayısı ile birlikte örnek büyüklüğünü kullanmaktadır (Schwarz, 1978). AIC, BIC ve AICC (Hurvich ve Tsai, 1989) sirasiyla 14 numaralı eşitlikte verildiği gibidir.

$$
\begin{aligned}
& A I C=-2 l l+2 p \\
& B I C=2 l l+p \ln (n) \\
& A I C C=A I C+\frac{2 p(p+1)}{n-p-1}
\end{aligned}
$$

Burada $l l$, Log-olabilirlik; $p$, parametre sayıs ve n, örnek büyüklügüüü gösterir. En küçük AIC, $\mathrm{BIC}$ ve AICC değerine sahip olan model en iyi model olarak belirlenir.

Çalışmanın istatistik analizleri için SAS (9.3) paket programından faydalanılmıştır.

\section{Bulgular ve Tartışma}

Çalışmanın herhangi bir döneminde ölüm ile sonuçlanan bireylere ilişkin ölçümlerin tamamı veri setinden uzaklaştırılmış ve 74 erkek etlik piliçe ait veri kullanılmıştır. Erkek etlik piliçlerin yumurtadan çıktıktan kesime kadar haftada bir olmak üzere, ölçümü yapılmış olan bireysel canlı ağırlıklarına (g) ilişkin tanımlayıcı istatistikler Tablo 1'de verilmiştir. Çalışma başlangıcında yumurtadan çıkış ağırlıkları ortalama $42.7 \mathrm{~g}$ iken, çalışmanın tamamlandığ 1 kesim öncesi ulaşılan ortalama canlı ağrılık 2250.16 g olmuştur. Varyasyon katsayısının 6.04 ila 16.46 arasında değiştiği görülmektedir. Etlik piliçler arası varyans, ölçüm zamanlarında sabit kalmayıp zamanla artış göstermiştir (Tablo 1).

Tablo 1. Erkek etlik piliçlerin yumurtadan çıktıktan kesime gidinceye yapılan canlı ağırlık ölçümlerine ait tanımlayıcı istatistikler

\begin{tabular}{ccccccc}
\hline Zaman & $\mathrm{n}$ & $\bar{X} \pm S S$ & Varyans & VK & Minimum & Maksimum \\
\hline 1 & 74 & $42.70 \pm 2.59$ & 6.65 & 6.04 & 38.6 & 49.6 \\
2 & 74 & $129.82 \pm 19.02$ & 361.58 & 14.65 & 67.8 & 164.4 \\
3 & 74 & $342.92 \pm 56.44$ & 3184.9 & 16.46 & 136.0 & 456.0 \\
4 & 74 & $655.86 \pm 103.07$ & 10623.65 & 15.72 & 250.0 & 856.0 \\
5 & 74 & $1091.84 \pm 170.66$ & 29124.71 & 15.63 & 444.0 & 1387.0 \\
6 & 74 & $1655.18 \pm 249.19$ & 62093.22 & 15.05 & 729.0 & 2135.0 \\
7 & 74 & $2250.16 \pm 314.52$ & 98921.95 & 13.98 & 1112.0 & 2802.0 \\
\hline
\end{tabular}

n: Gözlem sayısı, VK: Varyasyon katsayısı (\%)

Yumurta çıkışından kesime kadar olan süre içindeki gelişimi belirleyebilmek için başlangıçta lineer ve kuadratik büyüme modelleri çalıştırılmıştır. Her iki model için ML ve REML tahmin yöntemleri kullanılarak elde edilen uyum ölçütleri Tablo 2'de verilmiştir. Her iki genel doğrusal model bakımından Tablo 2 incelendiğinde, en küçük -2LL, AIC, AICC ve BIC değerlerinin REML tahmin yöntemi ile elde edildiği görülmektedir. Buna göre, her iki model için REML yöntemi ile elde edilen sonuçların literatür ile uyumlu olarak ML'den daha isabetli tahminler ürettiği ortaya konulmuştur. Patterson ve Thompson (1971) tarafından geliştirilen REML yöntemi, olabilirlik fonksiyonunu iki kısma ayrılması esasına dayanmaktadır. Bu kısımlardan biri sabit etkilerin olmadığ 1 kısım olup, REML yönteminde olabilirliğin sadece bu kısmı maksimize edilmektedir (Akkol, 1998; Ünalan ve Çankaya, 2012). Bu yönü ile avantajlı olan REML yönteminin ML'den daha sapmasız tahminler verdiği bildirilmiştir (Fırat ve Bek, 1997; Akkol, 1998).

ML ve REML tahmin yöntemleri lineer ve kuadratik modeller bakımından değerlendirildiğinde, kuadratik modelin daha küçük uyum ölçütlerine sahip olduğu Tablo 2'de görülmektedir. Daha sapmasız tahminler yapan REML yönteminde kuadratik model için uyum 
ölçütleri, -2LL, AIC, AICC ve BIC sirasıyla 44.5, 46.5 , 48.5, ve 45.9 olup kuadratik modelin, zamana bağlı olarak canlı ağırlıkta meydana gelen değişimi lineer modelden daha iyi açıkladığını ortaya koymaktadır. Zira hayvanlarda erken dönemlerdeki büyümenin genellikle doğrusal bir artış gösterdiği bilinmesine rağmen, yapılan çalışmalarda doğrusal artışı açıklayan modellerin her zaman tek başına yeterli olmayacağı ortaya konulmuştur (Bilgin ve Esenbuğa, 2003; Topal ve ark., 2004; Bayram ve Akbulut, 2009; Daskiran ve ark., 2010).

Tablo 2. Lineer ve kuadratik modele ilişsin uyum ölçütleri

\begin{tabular}{lrccc}
\hline \multirow{2}{*}{ Uyum ölçütleri } & \multicolumn{2}{c}{ Lineer model } & \multicolumn{2}{c}{ Kuadratik model } \\
\cline { 2 - 5 } & \multicolumn{1}{c}{ ML } & REML & \multicolumn{1}{c}{ ML } & REML \\
\hline -2LL & 93.1 & 73.5 & 57.0 & 44.5 \\
AIC & 99.1 & 75.5 & 65.0 & 46.5 \\
AICC & 107.1 & 76.8 & 85.0 & 48.5 \\
BIC & 99.0 & 75.1 & 64.8 & 45.9 \\
\hline
\end{tabular}

LL: Log olabilirlik, AIC: Akaiki bilgi ölçütü, AICC: Düzeltilmiş AIC, BIC: Bayes bilgi ölçütü

Gözlenen canlı ağırlık değerleri (CA), REML yöntemi kullanılarak doğrusal ve kuadratik modelden elde edilen tahmin değerlerinin (CA_Li: Doğrusal model ile elde edilen tahmin değeri, CA Ku: Kuadratik model ile elde edilen tahmin değeri) zaman bağlı değiş̧im grafiği Şekil 1'de sunulmuştur. Tablo 2'de verilen bilgileri destekleyen Şekil 1'de, CA değerlerine ait eğriye en yakın eğrinin CA_Ku değerleri ile elde edildiği görülmektedir.

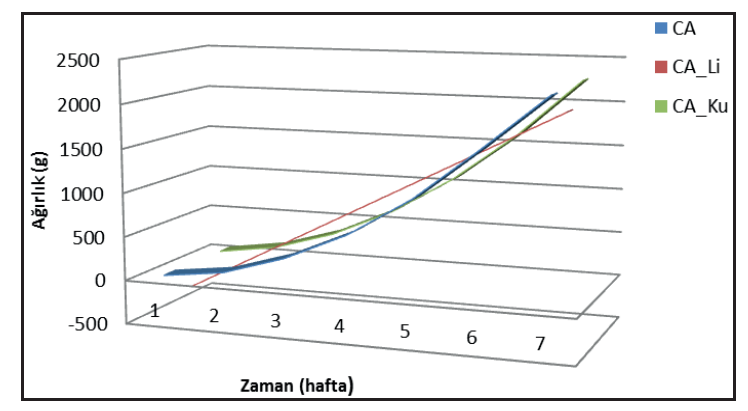

Şekil 1. Zamana göre gözlenen (CA), lineer (CA Li) ve kuadratik (CA_Ku) model ile tahmin edilen canlı ağırlıkların grafiği

Lineer ve kuadratik regresyon modelleri, REML yöntemi kullanılarak analiz edilmiş ve elde edilen tahmin ve standart hatalar Tablo 3'te verilmiştir. Lineer modelde zamanın doğrusal etkisinin anlamlı olduğu $(\mathrm{p}<0.001)$; kuadratik modelde zamanın hem doğrusal $(p<0.05)$ hem de kuadratik etkisinin $(\mathrm{p}<0.01)$ anlamlı olduğu Tablo 3 'te görülmekledir.

Tablo 3. Lineer ve kuadratik modele ait tahmin ve standart hatalar

\begin{tabular}{|c|c|c|c|c|c|}
\hline \multirow{2}{*}{ Katsayılar } & \multicolumn{2}{|c|}{ Lineer model } & \multirow{2}{*}{ Katsayılar } & \multicolumn{2}{|c|}{ Kuadratik model } \\
\hline & $\overline{\bar{x}} \pm \mathrm{SH}$ & $\mathrm{p}$ & & $\overline{\bar{X}} \pm \mathrm{SH}$ & $\mathrm{p}$ \\
\hline$\beta_{0}$ & $-235.43 \pm 151.26$ & 0.180 & $\beta_{0}$ & $34.60 \pm 16.36$ & 0.102 \\
\hline$\beta_{1}$ & $372.22 \pm 41.95$ & 0.001 & $\beta_{1}$ & $48.17 \pm 12.77$ & 0.020 \\
\hline & & & $\beta_{2}$ & $54.01 \pm 2.04$ & 0.001 \\
\hline
\end{tabular}

SH: Standart hata

Çalışmanın bir sonraki aşamasında çok seviyeli doğrusal modeller kullanılarak etlik piliçlerin canlı ağırlıklarındaki değişim modellenmeye çalışılmıştır. Bu amaçla, Model I, Model II ve Model III, hem ML hem de REML tahmin yöntemleri kullanılarak analiz edilmiştir. Her iki tahmin yöntemi için AR1, CS, UN, Toep, ARH1, CSH ve ToepH kovaryans yapıları kullanılmıs ve uyum ölçütleri Tablo 4'te verilmiştir. Tablo 4'te RIGLS tahmin yöntemi ile elde edilen uyum ölçütlerinin IGLS yöntemi ile elde edilenlerden daha küçük olduğu görülmektedir. Buna göre çalışma verisi için RIGLS tahmin yönteminin IGLS'den daha iyi olduğu ortaya konulmuştur. Elde edilen bu sonuç, literatür ile uyumlu olmuştur (Browne, 1998; Browne ve Draper, 2001; Goldstein, 2011).

Çalışmada kullanılan Model I için RIGLS tahmin yöntemi kullanılarak elde edilen uyum ölçütleri değerlendirildiğinde, UN ve Toep, kovaryans yapılarının aynı değere sahip olup diğerlerinden daha küçük olduğu görülmektedir. Model II ve Model III için en küçük uyum ölçütlerinin UN kovaryans yapısı ile sağlandığı görülmektedir (Tablo 4). Zira en küçük -2LL, AIC, AICC, BIC değerleri UN kovaryans yapısı kullanılınca elde edilmiştir. Yapılan çalışmalarda tekrarlamalı olarak elde edilen ölçümlerin analizinde modeli açıklayan en iyi kovaryans yapısının UN olduğu ortaya konulmuş ve bu çalışmanın sonuçları ile uyumlu olmuştur (Ser ve ark., 2013; Akkol, 2018; Akkol ve ark., 2019). RIGLS tahmin yöntemi ve UN kovaryyans yapısı kullanılarak elde edilen uyum ölçütleri incelendiğinde canlı ağırlıktaki değişimin açıklandığı en iyi modelin, Model III olduğu görülmektedir (Tablo 4). 
Tablo 4. Model I, Model II ve Model III için ML ve REML tahmin yöntemleri ve farklı kovaryans yapılarına göre model uyum ölçütleri

\begin{tabular}{|c|c|c|c|c|c|c|c|c|c|}
\hline Model & Tahmin yöntemi & Uyum ölçütü & AR1 & $\mathrm{CS}$ & UN & Toep & ARH1 & $\mathrm{CSH}$ & ToepH \\
\hline \multirow{8}{*}{ Model I } & \multirow{4}{*}{ IGLS/ML } & $-2 l l$ & 7186.7 & 7186.7 & 7186.7 & 7186.7 & 7186.7 & 7186.7 & 7186.7 \\
\hline & & AIC & 7196.7 & 7196.7 & 7194.7 & 7194.7 & 7196.7 & 7196.7 & 7194.7 \\
\hline & & AICC & 7196.8 & 7196.8 & 7194.8 & 7194.8 & 7196.8 & 7196.8 & 7194.8 \\
\hline & & $\mathrm{BIC}$ & 7208.2 & 7208.2 & 7203.9 & 7203.9 & 7208.2 & 7208.2 & 7203.9 \\
\hline & \multirow{4}{*}{ RIGLS/REML } & $-2 l l$ & 7174.4 & 7174.4 & 7174.4 & 7174.4 & 7174.4 & 7174.4 & 7174.4 \\
\hline & & AIC & 7180.4 & 7180.4 & 7178.4 & 7178.4 & 7180.4 & 7180.4 & 7178.4 \\
\hline & & AICC & 7180.4 & 7180.4 & 7178.4 & 7178.4 & 7180.4 & 7180.4 & 7178.4 \\
\hline & & BIC & 7187.3 & 7187.3 & 7183.0 & 7183.0 & 7187.3 & 7187.3 & 7183.0 \\
\hline \multirow{8}{*}{ Model II } & \multirow{4}{*}{ IGLS/ML } & $-2 l l$ & 7107.1 & 7090.4 & 7025.7 & 7090.4 & 7105.9 & 7090.4 & 7105.9 \\
\hline & & $\mathrm{AIC}$ & 7115.1 & 7100.4 & 7035.7 & 7100.4 & 7115.9 & 7100.4 & 7115.9 \\
\hline & & $\mathrm{AICC}$ & 7115.2 & 7100.5 & 7035.8 & 7100.5 & 7116.0 & 7100.5 & 7116.0 \\
\hline & & $\mathrm{BIC}$ & 7124.3 & 7111.9 & 7047.2 & 7111.9 & 7127.4 & 7111.9 & 7127.4 \\
\hline & \multirow{4}{*}{ RIGLS/REML } & $-2 l l$ & 7094.5 & 7078.0 & 7014.2 & 7078.0 & 7093.3 & 7078.0 & 7093.3 \\
\hline & & AIC & 7098.5 & 7084.0 & 7020.2 & 7084.0 & 7099.3 & 7084.0 & 7099.3 \\
\hline & & AICC & 7098.5 & 7084.1 & 7020.3 & 7084.1 & 7099.4 & 7084.1 & 7099.4 \\
\hline & & BIC & 7103.1 & 7090.9 & 7027.1 & 7090.9 & 7106.2 & 7090.9 & 7106.2 \\
\hline \multirow{8}{*}{ Model III } & \multirow{4}{*}{ IGLS/ML } & $-2 l l$ & 5789.0 & 5789.0 & 5760.1 & 5789.0 & 5765.4 & 5789.0 & 5765.4 \\
\hline & & AIC & 5801.0 & 5801.0 & 5774.1 & 5801.0 & 5777.4 & 5801.0 & 5777.4 \\
\hline & & AICC & 5801.2 & 5801.2 & 5774.3 & 5801.2 & 5777.6 & 5801.2 & 5777.6 \\
\hline & & $\mathrm{BIC}$ & 5814.9 & 5814.9 & 5790.2 & 5814.9 & 5791.3 & 5814.9 & 5791.3 \\
\hline & \multirow{4}{*}{ RIGLS/REML } & $-2 l l$ & 5778.4 & 5778.4 & 5750.1 & 5778.4 & 5755.1 & 5778.4 & 5755.1 \\
\hline & & AIC & 5784.4 & 5784.4 & 5758.1 & 5784.4 & 5761.1 & 5784.4 & 5761.1 \\
\hline & & $\mathrm{AICC}$ & 5784.4 & 5784.4 & 5758.1 & 5784.4 & 5761.1 & 5784.4 & 5761.1 \\
\hline & & $\mathrm{BIC}$ & 5791.3 & 5791.3 & 5767.3 & 5791.3 & 5768.0 & 5791.3 & 5768.0 \\
\hline
\end{tabular}

ll: Log olabilirlik, AIC: Akaike bilgi ölçütü, AICC: Düzeltilmiş Akaike bilgi ölçütü, BIC: Bayes bilgi ölçütü, AR1: Birinci derecede Autoregressive, CS: Bileşik simetri, UN: Yapısal olmayan, Toep: Toepliz, ARH1: Heterojen birinci dereceden Autoregresive, CSH: Heterojen bileşik simetri, ToepH: Heterojen toepliz

Model I, Model II ve Model III için RIGLS tahmin yöntemi ve UN kovaryans yapıs1 kullanılarak elde edilen tahmin ve standart hata değerleri Tablo 5'te verilmiştir. Tablo 5'te Model I, II ve III için tüm sabit etkiler ve seviye-2 ve seviye-1 hataları anlamlı bulunmuştur $(\mathrm{p}<0.01)$. $\mathrm{Bu}$ çalışmada iki seviyeli koşulsuz büyüme modelleri içinde en iyi model Model III olarak belirlenmiştir. Model II kullanıldığında seviye-1 hata miktarında 13111 (56664-43553) birim ve
Model III kullanıldığında seviye-1 hata miktarında Model II'ye göre 41318.17 (43553-2234.83) birim azalma meydana gelmiştir. Seviye 1 hata terimindeki bu azalma modele şansa bağlı etkilerin dahil edilmesi yani çok seviyeli modellerin kullanılması ile açıklanmaktadır (Goldstein, 2011). Bu sonuç, Model III'ün diğer modellere göre canlı ağırlıktaki değişimi daha iyi açıkladığının bir diğer açıklamasıdır. Tablo 5'te civcivlerin yumurtadan çıkış ağrılıkları ortalama $34.60 \mathrm{~g}\left(\beta_{00}\right)$, zamanın

Tablo 5. Model I, Model II ve Model III için REML tahmin yöntemi kullanılarak elde edilen tahmin ve standart hatalar

\begin{tabular}{ccccccccc}
\hline Model & Sabit etki & $\bar{X} \pm S S$ & $\mathrm{t}$ & $\mathrm{p}$ & Şansa bağlı etki & $\bar{X} \pm S S$ & \multicolumn{1}{c}{$\mathrm{Z}$} & $\mathrm{p}$ \\
\hline \multirow{2}{*}{ Model I } & $\beta_{00}$ & $-235.43 \pm 21.42$ & -10.99 & 0.001 & $\sigma_{u_{0}}^{2}$ & $7653.49 \pm 2662.82$ & 2.87 & 0.002 \\
& $\beta_{10}$ & $372.21 \pm 5.23$ & 71.18 & 0.001 & $\sigma_{e}^{2}$ & $56664.00 \pm 3807.32$ & 14.88 & 0.001 \\
\hline \multirow{2}{*}{ Model II } & $\beta_{00}$ & $-235.43 \pm 16.53$ & -14.24 & 0.001 & $\sigma_{u_{0}}^{2}$ & 0 & - & - \\
& $\beta_{10}$ & $372.21 \pm 17.49$ & 21.28 & 0.001 & $\sigma_{u_{01}}$ & $-16411.00 \pm 1717.46$ & -9.56 & 0.001 \\
& & & & & $\sigma_{u_{1}}^{2}$ & $21082.00 \pm 3070.62$ & 6.87 & 0.001 \\
& & & & & $\sigma_{e}^{2}$ & $43553.00 \pm 2926.35$ & 14.88 & 0.001 \\
\hline \multirow{2}{*}{ Model III } & $\beta_{00}$ & $34.60 \pm 6.17$ & 5.61 & 0.001 & $\sigma_{u_{0}}^{2}$ & $1116.47 \pm 364.63$ & 3.06 & 0.001 \\
& $\beta_{10}$ & $48.17 \pm 7.30$ & 6.58 & 0.001 & $\sigma_{u_{01}}$ & $-2006.07 \pm 397.66$ & -5.04 & 0.001 \\
& $\beta_{20}$ & $54.01 \pm 0.60$ & 90.07 & 0.001 & $\sigma_{u_{1}}^{2}$ & $2927.52 \pm 497.80$ & 5.88 & 0.001 \\
& & & & & $\sigma_{e}^{2}$ & $2234.83 \pm 164.53$ & 13.58 & 0.001 \\
\hline
\end{tabular}

SS: Standart sapma 
ortalama lineer etkisi, yani zamanın doğrusal artışı ile canlı ağırlıkta meydana gelen ortalama değişim miktarı $48.17 \mathrm{~g}\left(\beta_{10}\right)$ ve zamanın kuadratik artışı ile canlı ağırlıkta meydana gelen ortalama değişim miktarı $54.01 \mathrm{~g}\left(\beta_{20}\right)$ olduğu görülmektedir. $\mathrm{Bu}$ değerler, Tablo 3'te verilen kuadratik model ile aynı olmuştur. Ancak standart hataların miktarında önemli ölçüde azalma olduğu dikkat çekmektedir. Bunun nedeni Model III'ün iki seviyeli bir büyüme modeli olarak bireyler arasındaki varyasyonu dikkate almasından kaynaklanmaktadır. Model III'de yer alan şansa bağlı etkilerden $\sigma_{u_{0}}^{2}$ 'nin anlamlı olması etlik piliçlerin yumurtadan çıkış ağırlıklarının birbirlerinden anlamlı miktarda farklı olduğunu $(\mathrm{p}<0.01)$ ve $\sigma_{u_{1}}^{2}$ 'nin anlamlı olması ise her bir etlik pilicin büyüme eğrisinin bir diğerinden anlamlı miktarda farklı olduğunu $(p<0.01)$ göstermektedir. Kesim noktası ve eğimdeki birlikte değişimin ifadesi olan kovaryans $\left(\sigma_{u_{01}}\right)$ değeri negatif işaretli olup anlamlı $(\mathrm{p}<0.01)$ bulunmuştur (Tablo 5). Buna göre yumurtadan çıkış ağırlığı yüksek olan bir civcivin daha sonraki haftalarda kazandığı canlı ağırlık daha düşük, yumurtadan çıkış ağırlığı daha düşük olan bir civcivin ise sonraki haftalarda daha yüksek canlı ağırlık kazandığını ortaya koymaktadır.

Genel doğrusal modeller ve iki seviyeli koşulsuz modeller kullanılarak elde edilen uyum ölçütleri Tablo 6'da verilmiştir. Uyum ölçütleri için değerlendirme yapıldığında, genel doğrusal ve çok seviyeli doğrusal modeller ayrı başlıklar olarak dikkate alınmıştır. En küçük uyum ölçütüne sahip olan model en iyi model olması nedeniyle uyum ölçütleri bakımından modeller değerlendirilmiştir (Akaike, 1974; Schwarz, 1978; Hurvich ve Tsai, 1989). Buna göre genel doğrusal modeller kullanıldığında en küçük uyum ölçütlerine (-2ll, AIC, AICC ve BIC) kuadratik model sahip olurken, iki seviyeli doğrusal modeller kullanıldığında Model III sahip olmuştur. Tablo 6'da verilen olabilirlik oran test (Likelihood Ratio Test, LRT) sonuçları, genel doğrusal modellerden kuadratik modelin ve iki seviyeli doğrusal modellerden Model III'ün en iyi model olduğunu ortaya koymuştur $(\mathrm{p}<0.01)$.

Tablo 6. Çalışmada kullanılan büyüme modellerine ilişkin uyum ölçütleri

\begin{tabular}{|c|c|c|c|c|c|c|c|}
\hline & $-2 l l$ & $\mathrm{AIC}$ & AICC & $\mathrm{BIC}$ & LRT test & SD & $\chi^{2}$ \\
\hline \multicolumn{8}{|c|}{ Genel doğrusal regresyon modelleri } \\
\hline Lineer & 73.5 & 75.5 & 76.8 & 75.1 & - & - & \\
\hline Kuadratik & 44.5 & 46.5 & 48.5 & 45.9 & 29 & 1 & ** \\
\hline \multicolumn{8}{|c|}{ İki seviyeli doğrusal regresyon modelleri } \\
\hline Model I & 7174.4 & 7178.4 & 7178.4 & 7183 & - & & \\
\hline Model II & 7014.2 & 7020.2 & 7020.3 & 7027.1 & 160.2 & 2 & ** \\
\hline Model III & 5750.1 & 5758.1 & 5758.1 & 5767.3 & 1264.1 & 1 & ** \\
\hline
\end{tabular}

ll: Log olabilirlik, AIC: Akaiki bilgi ölçütü, AICC: Düzeltilmiş AIC, BIC: Bayes bilgi ölçütü, SD: Serbestlik derecesi, $\chi^{2}:$ Ki kare, **: p<0.01

Büyüme eğrilerinin çalışıldı̆̆ hem genel doğrusal hem de doğrusal olmayan modellerde her bir ölçüm zamanında alınan bireysel ölçümlerin ortalamasını kullanmaktadır. Buna rağmen çok seviyeli doğrusal regresyon modelleri başlığ altında incelenen iki seviyeli koşulsuz büyüme modellerinde bireysel ölçümler analize tabi tutulur. Bu nedenle, genel doğrusal ve iki seviyeli doğrusal modellere ait uyum ölçütlerinin kıyaslanması yerine, kullanilan modeller tahmin hassasiyeti bakımından karşılaştırılmıştır. Buna göre Tablo 3 'te kuadratik model ve Tablo 5'teki Model III için sabit etkiler için tahmin ve standart hatalar değerlendirildiğinde, Model III ile elde edilen sabit etkilerin daha küçük standart hatalara sahip olduğu görülmektedir. $\mathrm{Bu}$ sonuç, çalışma verisi için Model III'ün kuadratik modelden daha hassas tahminler ürettiğini ortaya koymaktadır. Zira tekrarlamalı ölçüm verilerinde bireysel farklılıkların dikkate alınmasıyla, seviye-1 hata miktarında azalma olduğu literatürde bildirilmiştir
(Singer, 1998; Raudenbush ve Bryk, 2002; Goldstein, 2011; Akkol ve ark., 2018). Buna göre genel çalışmada kullanılan modellerden verideki değișimi en iyi açıklayan model hem ortalama hem de bireysel büyüme eğrilerinin tahmin edildiği Model III olmuştur. Model III için bireysel büyüme eğrileri Şekil 2'de verilmiştir. Şekil 2'de etlik erkek piliçlerin her birinin hem yumurtadan çıkış ağırlıklarının hem de kesime gidinceye kadar canlı ağırlıklarında meydana gelen artış miktarlarının birbirlerinden farklı olduğu görülmektedir. Dolayısıyla Şekil 2'de, çalışmada büyüme verisinin analiz edildiği 74 erkek pilicin her biri için ayrı büyüme eğrisi yer almaktadır.

\section{Sonuçlar}

Ekonomik ve sürdürülebilir bir hayvancılık işletmesinde büyüme performansı önemli bir özellik olarak yerini korumaktadır. Büyüme, ırklar arasında olduğu kadar aynı ırk içindeki bireyler 


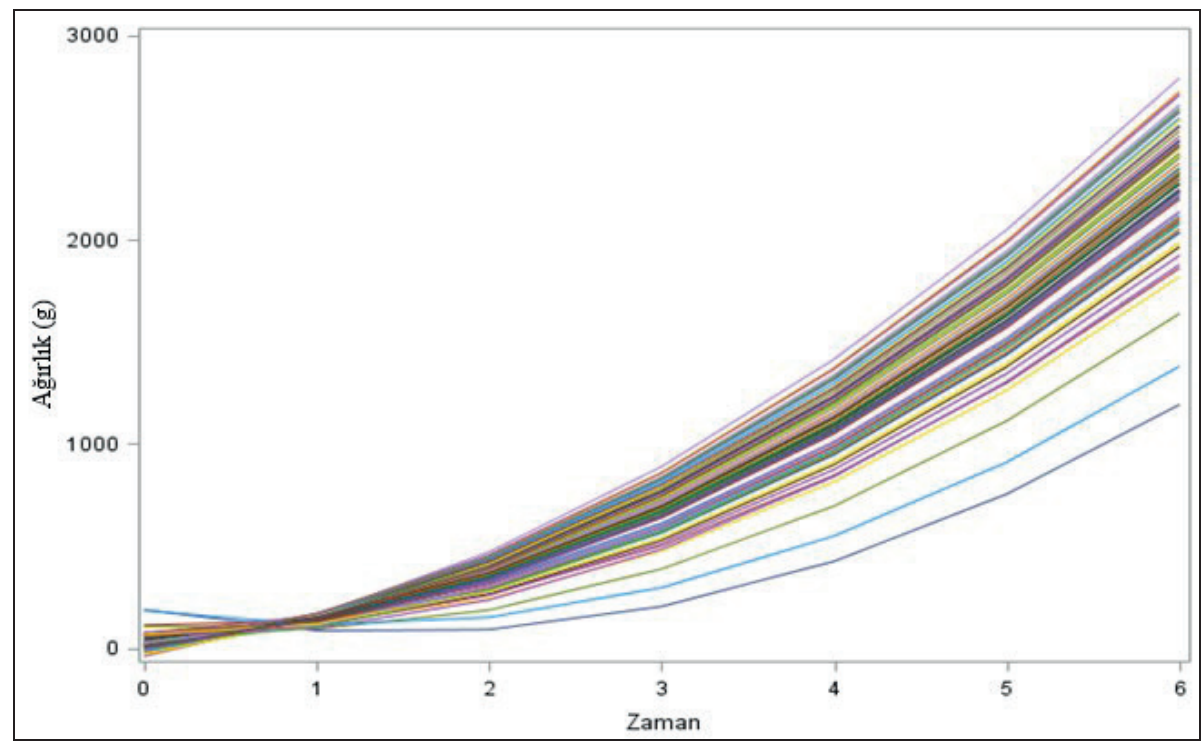

Şekil 2. Model III (kesim noktası ve eğimin şansa bağlı olduğu kuadratik büyüme modeli) kullanılarak elde edilen bireysel büyüme eğrileri

arasında da farklı olmaktadır. Büyüme verileri için çok düzeyli/hiyerarşik modeller kullanılması, veriler arasındaki kovaryans yapısının tanımlanmasından dolayı daha hassas tahminlerin elde edilmesine ve dolayısıyla doğru yorumlamalara imkân tanımaktadır. Bu çalışmada, genel doğrusal ve çok seviyeli/hiyerarşik doğrusal büyüme modelleri tartışılmış ve iki seviyeli koșulsuz büyüme modellerinden Model III'ün büyüme verilerindeki değişimi en iyi açıklayan model olduğu ortaya konulmuştur. Doğrusal olmayan büyüme eğrisi modelleri araştırmacılar tarafindan siklıkla kullanılmaktadır. Ancak büyüme verileri arasındaki kovaryansın dikkate alınmadığı bu modellerin genel doğrusal büyüme modellerinde olduğu gibi çok düzeyli modelleme mantığında kullanımına olanak sağlayacak çalışmaların yapılması gerekmektedir. Zira Türkiye'nin farklı bölgelerinde özellikle de yüksek rakıma sahip Doğu Anadolu Bölgesi'nde yetiştirilecek etlik piliçler için, farklı büyüme modelleri kullanılarak yapılacak karşılaştırmalar ile uygun etlik piliç türlerinin, cinsiyetlerinin ve kesim yaşlarının belirleneceği yeni çalışmalara ihtiyaç duyulmaktadır.

\section{Kaynaklar}

Akaike, H., 1974. A new look at the statistical model identification. IEEE Transaction on Automatic Control, 19(6): 716-724.

Akbulut, Ö., Bayram, B., Tüzemen, N., 2004. Esmer sığırlarda büyümenin doğrusal olamayan modellerle analizi. Atatürk Üniversitesi Ziraat Fakültesi Dergisi, 35(3-4):165-168.
Akkol, S.G., 1998. REML ve DFREML yöntemlerinin ıslah amaçlı çalışmalarda kullanılması. Yüksek lisans tezi, Yüzüncü Y1l Üniversitesi Fen Bilimleri Enstitüsü, Van.

Akkol, S., Gökdal, Ö., Atay, O., 2019. Evaluation of individual growth performance of goat kids by using multilevel models. International Journal of Scientific and Technological Research, 5(3): 88-98.

Akkol, S., Karakuş, F., Cengiz, F., 2018. Multilevel analysis for repeated measures data in lambs1. Journal of Agricultural Sciences, 24(2): 218-226.

Alkan, S., Birgül, Ö.B., 2016. Etlik piliçlerde embriyonun erken ve geç gelişim dönemlerinde yapılan yüksek 1sıl uygulamaların büyüme özelliklerine etkileri. Mediterranean Agricultural Sciences, 29(3): 149-154.

Araújo, C.C., Rodrigues, K.F., Vieira Vaz, R.G.M., Conti, A.C.M., Amorim, A.F., Campos, C.F.A., 2018. Analysis of growth curves in different lineages of Caipira broiler type. Acta Scientiarum Animal Sciences, v40: e38806.

Bayram, B., Akbulut, Ö., 2009. Esmer ve Siyah Alaca sığırlarda büyüme eğrilerinin doğrusal ve doğrusal olmayan modellerle analizi. Hayvansal Üretim, 50(2): 33-40.

Bilgin, Ö.C., Esenbuğa, N., 2003. Doğrusal olmayan büyüme modellerinde parametre tahmini. Hayvansal Üretim, 44(2): 81-90.

Breslow, N.E., Clayton, D.G., 1993. Approximate inference generalized linear mixed models. Journal of the American Statistical Association, 88(421): 925.

Browne, W.J., 1998. Applying MCMC methods to multilevel models. $\mathrm{PhD}$ dissertation, (http://seis.bris. ac.uk/-frwjb/materials/wbphd.pdf), (Erișim tarihi: 10.11.2019). 
Browne, W.J., Draper, D., 2001. A Comparison of Bayesian and Likelihood-Based Methods for Fitting Multilevel Models. Computational Statistics. Institute of Education, University of London. UK.

Çolak, C., Orman, M.N., Ertuğrul, O., 2006a. Simental X Güney Anadolu kırmızısı sığırlarının beden ölçümleri için basit doğrusal ve lojistik büyüme modelleri. Ankara Üniversitesi Veteriner Fakültesi Dergisi, 53(3): 195-199.

Çolak, C., Orman, M.N., Ertuğrul, O., 2006b. Simental $\mathrm{X}$ Güney Anadolu kırmızısı sığırlarına ait canlı ağırlık ölçümlerine dayanan için doğrusal ve doğrusal olmayan büyüme eğrileri. Lalahan Hayvancılık Araştırma Enstitüsü Dergisi, 46(1): 15.

Daskiran, I., Koncagul, S., Bingol, M., 2010. Growth characteristics of indigenous norduz female and male lambs. Journal of Agricultural Sciences, 16(1): 62-69.

Demuner, L.F., Suckeveris, D., Muñoz, J.A., Caetano, V.C., Lima, C.G., Filho, D.E.F., Faria, D.E., 2017. Adjustment of growth models in broiler chickens. Pesquisa Agropeccuaria Brasileira, 52(12): 12411252.

Efe, E., 1990. Büyüme eğrileri. Doktora tezi (Basılmamıș), Çukurova Üniversitesi Fen Bilimleri Enstitüsü, Adana.

Eleroğlu, H., Yıldırım, A., Canikli, A., Duman, M., Bircan, H., 2018. Analysis of growth curves of guinea (Numida meleagris) fed diets containing dry oregano (Origanum vulgare L.) in an organik sistem. Ciencia Investigación Agraria, 45(2): 99108.

Firat, M.Z., Bek, Y., 1997. Varyans unsurlarının tahmini için maksimum olabilirlik metotlarının karşılaştırmalı olarak incelenmesi. Çukurova Üniversitesi Ziraat Fakültesi Dergisi, 12(1): 1-8.

Ghaderi-Jzefrehei, M., Rafeie, F., Behzadi, M.R.B., Nazari, S., Dolatabadi, M., Samadian, F., Najafabadi, H.A., 2018. Simple hierarchical and general nonlinear growth modeling in sheep. Turkish Journal of Veterinary And Animal Sciences, 42(4): 326-334.

Goldstein, H., 2011. Multilevel Statistical Models. $4^{\text {th }}$ Ed., John Wiley \& Sons, Ltd. Chichester, United Kingdom.

Hedeker, D., 2004. An introduction to growth modeling. In: D. Kaplan (Ed.), The sage handbook of quantitative methodology for the social sciences, Thou-Sand Oaks, CA: Sage Publications, pp. 215234.

Hurvich, C.M., Tsai, C.L., 1989. Regression and time series model selection in small samples. Biometrika, 76(2): 297-307.

Kocabaş, Z., Kesici, T., Eliçin, A., 1997. Akkaraman İvesi X Akkaraman ve Malya X Akkaraman kuzularında büyüme eğrisi. The Turkish Journal of Veterinary and Animal Sciences, 21(3): 267-275.

Kristjansson, S.D., Kircher, J.C., Webb, A.K., 2007. Multilevel models for repeated measures research signs in psychophysiology: An introduction to growth curve modeling. Psychophysiology, 44(5): 728-736.

Lin, X., Breslow, N.E., 1996. Bias correction in generalized linear mixed models with multiple components of dispersion. Journal of The American Statistical Association, 91(435): 1007-1016.

Masoudi, A., Azarfar, A., 2017. Comparison of nonlinear models describing growth curves of broiler chickens fed on different levels of corn bran. International Journal of Avian and Wildlife Biology, 2(1): 1-7.

Michalczuk, M., Damaziak, K., Goryl, A., 2016. Sigmoid models for the growth curves in mediumgrowing meat type chickens, raised under semi confined conditions. Annals Animal Science, 16(1): 65-77.

Patterson, H.D., Thompson, R., 1971. Recovery of interblock information when block sizes are unequal. Biometrika, 58(3): 545-554.

Raudenbush, S.W., Bryk, A.S., 2002. Hierarchical Linear Models: Applications and Data Analysis Methods. 2nd Ed., Newbury Park, CA: Sage.

Schwarz, G., 1978. Estimating the dimensions of a model. Annals of Statistics, 6(2): 461-464.

Ser, G., Kaki, B., Yeşilova, A., Yılmaz, A., 2013. Genel doğrusal karışık modellerde farklı kovaryans yapıları ve tahmin yöntemlerinin performanslarının karşılaştırılması. Hayvansal Üretim, 54(2): 18-23.

Simsek, B., Firat, M.Z., 2011. Application of multilevel analysis in animal sciences. Applied Mathematics and Computation, 218(3): 1067-1071.

Singer, J.D., 1998. Using SAS PROC MIXED to fit multilevel models, hierarchical models and individual growth models. Journal of Educational and Behavioral Statistics, 23(4): 323-355.

Topal, M., Ozdemir, M., Aksakal, V., Yildiz, N., Dogru, U., 2004. Determination of the best nonlinear function in order to estimate growth in Morkaraman and Awassi lambs. Small Ruminant Research, 55(13): 229-232.

Ünalan, A., Çankaya, S., 2012. Jersey sığırlarda süt verimine ait varyans unsurlarının farklı yöntemlerle tahmini. Anadolu Tarım Bilimleri Dergisi, 27(1): 4147.

Van Der Leeden, R.,1998. Multilevel analysis of repeated measures data. Quality and Quantity, 32(1): 15-29.

Yıldız, G., Soysal, M.İ., Gürcan, E.K., 2009. Tekirdağ ilinde yetiştirilen Karacabey Merinosu X Kıvırcık Melezi kuzularda büyüme eğrisinin farklı modellerle belirlenmesi. Tekirdağ Ziraat Fakültesi Dergisi, 6(1): 11-19.

Zhao, Z., Li, S., Huang, H., Li, C., Wang, Q., Xue, L., 2015. Comparative study on growth and developmental model of indigenous chicken breeds in China. Open Journal of Animal Sciences, 5(02): 219-223. 